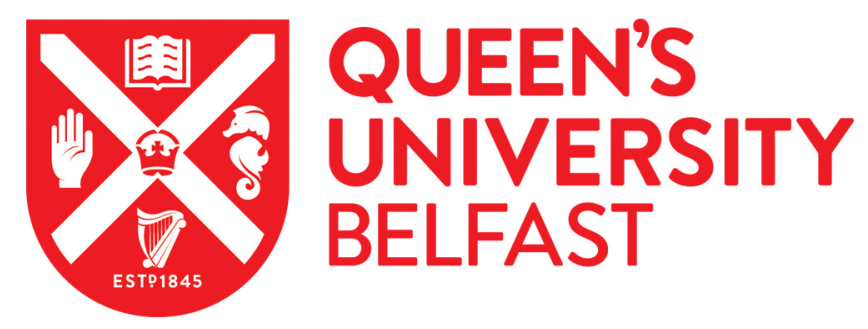

\title{
Incorporating Stories of Sedatives, Spoiled Sweet Clover Hay, and Plants from the Amazon Rainforest into a Pharmaceutical Chemistry Course To Engage Students and Introduce Drug Design Strategies
}

Larrañeta, E. (2018). Incorporating Stories of Sedatives, Spoiled Sweet Clover Hay, and Plants from the

Amazon Rainforest into a Pharmaceutical Chemistry Course To Engage Students and Introduce Drug Design Strategies. Journal of chemical education. https://doi.org/10.1021/acs.jchemed.8b00063

Published in:

Journal of chemical education

Document Version:

Peer reviewed version

Queen's University Belfast - Research Portal:

Link to publication record in Queen's University Belfast Research Portal

Publisher rights

(c) 2018 American Chemical Society and Division of Chemical Education, Inc. This work is made available online in accordance with the publisher's policies. Please refer to any applicable terms of use of the publisher

\section{General rights}

Copyright for the publications made accessible via the Queen's University Belfast Research Portal is retained by the author(s) and / or other copyright owners and it is a condition of accessing these publications that users recognise and abide by the legal requirements associated with these rights.

\section{Take down policy}

The Research Portal is Queen's institutional repository that provides access to Queen's research output. Every effort has been made to ensure that content in the Research Portal does not infringe any person's rights, or applicable UK laws. If you discover content in the Research Portal that you believe breaches copyright or violates any law, please contact openaccess@qub.ac.uk. 
Incorporating Stories of Sedatives, Spoiled Sweet Clover Hay, and Plants from the Amazon Rainforest into a Pharmaceutical Chemistry Course to Engage Students and Introduce Drug Design Strategies

Eneko Larrañeta*

School of Pharmacy, Queen's University Belfast, 97 Lisburn Road, Belfast, BT9 7BL, UK.

${ }^{*}$ Corresponding author

Dr. Eneko Larrañeta

Lecturer in Pharmaceutical Sciences

School of Pharmacy,

Queens University Belfast, Medical Biology Centre,

97 Lisburn Road,

Belfast

BT9 7BL, UK

Tel: $+44(0) 2890972360$

Fax: +44 (0) 2890247794

Email: e.larraneta@qub.ac.uk 


\begin{abstract}
This article describes three historical cases of drug discovery and how they were adapted as examples to teach chemical analysis to students pursuing a pharmacy (UK MPharm) and pharmaceutical sciences (BSc Pharmaceutical Sciences) degree. The selected cases were the synthesis of benzodiazepines and the discovery of warfarin and neuromuscular blocking agents. These examples present some peculiarities as they were developed in special circumstances and without the assistance of modern chemical analysis techniques. By incorporating these examples in a pharmaceutical chemistry class, the students became aware of the importance of chemical knowledge in overcoming technical limitations. Moreover, the examples were designed to stimulate the interest of the students in the subject. Three case studies including drug discovery examples were implemented in a chemistry module delivered to pharmacy students. The views of the students (48 MPharm and 7 BSc pharmaceutical sciences) about these lectures was obtained by using a questionnaire. After delivering the lectures, the majority of the students (64\%) thought that understanding the history behind some scientific discoveries was important for them. Additionally, they considered that the selected historical examples were not only interesting but useful to understand the material delivered in the pharmaceutical chemistry module $(75 \%$ of the students).
\end{abstract}

Keywords: Analytical Chemistry; Drugs / Pharmaceuticals; History / Philosophy; Instrumental Methods; Medicinal Chemistry; 


\section{Graphical Abstract}

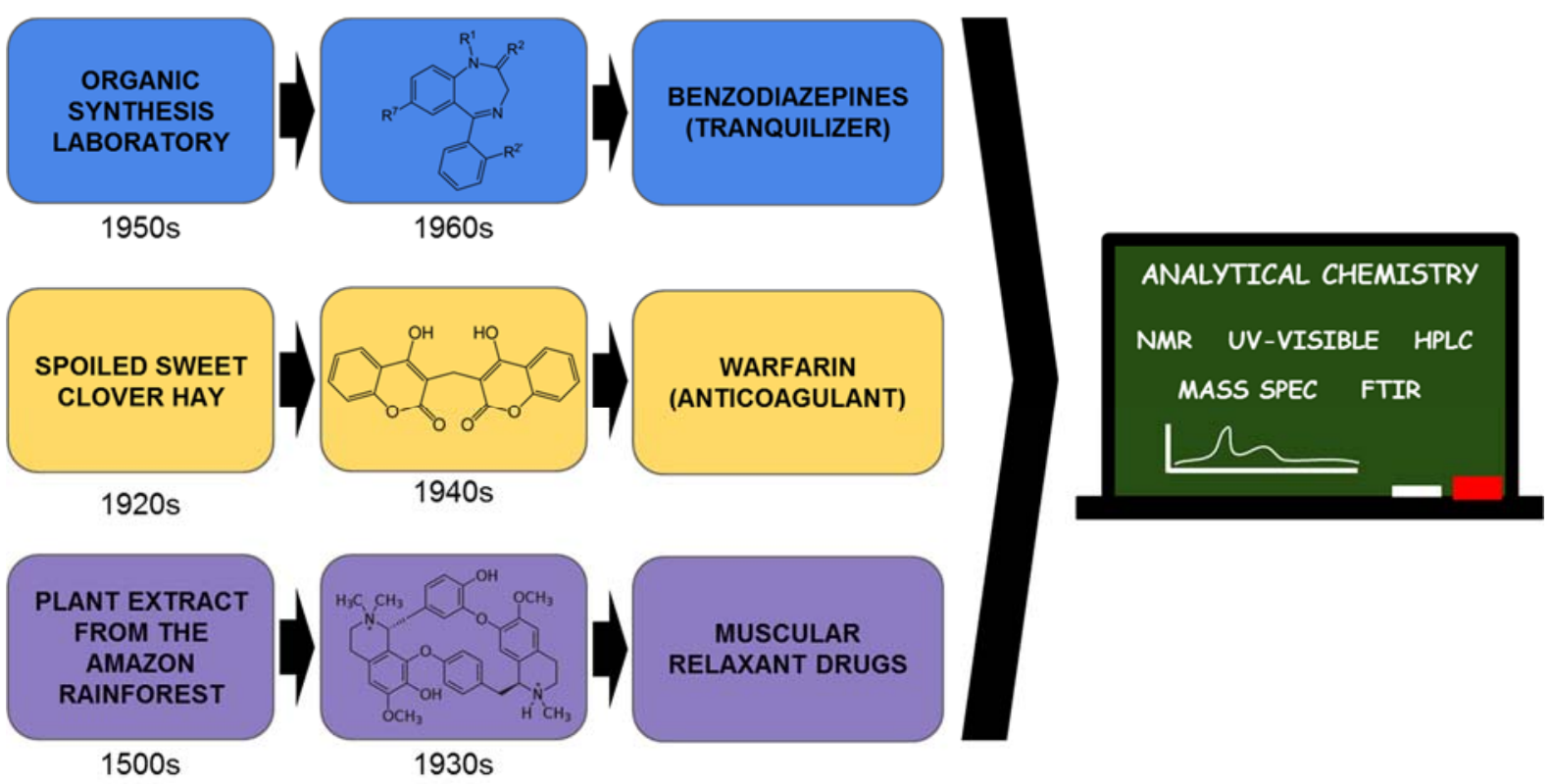




\section{Introduction}

Teaching chemistry in a pharmacy degree programs can be challenging as some students struggle to recognize how this subject is relevant to their studies ${ }^{1}$. A good teaching approach to overcome this challenge is to add some examples of chemical related topics to the lectures that are important for the clinical environment that the students will be working in ${ }^{1,2}$.

Students at Queen's University Belfast enrolled in the 3rd year of two professional programs, MPharm degree in pharmacy and BSc degree in pharmaceutical sciences, take a module titled "Pharmaceutical Analysis and Drug Design". Within this module, two of the one hour lectures were devoted to delivering three chemical case studies. The cases were centred on the discovery of three clinically relevant drugs during the $20^{\text {th }}$ century, including examples of how they were developed without using modern analysis techniques.

Nowadays, chemical analysis is based mainly on instrumental techniques. However, analytical chemists use their chemical knowledge to overcome technical limitations. For example, when an analyst encounters a molecule that cannot be analyzed using the available techniques, a possible approach is to transform the analyte into a new molecule that can be easily analyzed (chemical derivatization).

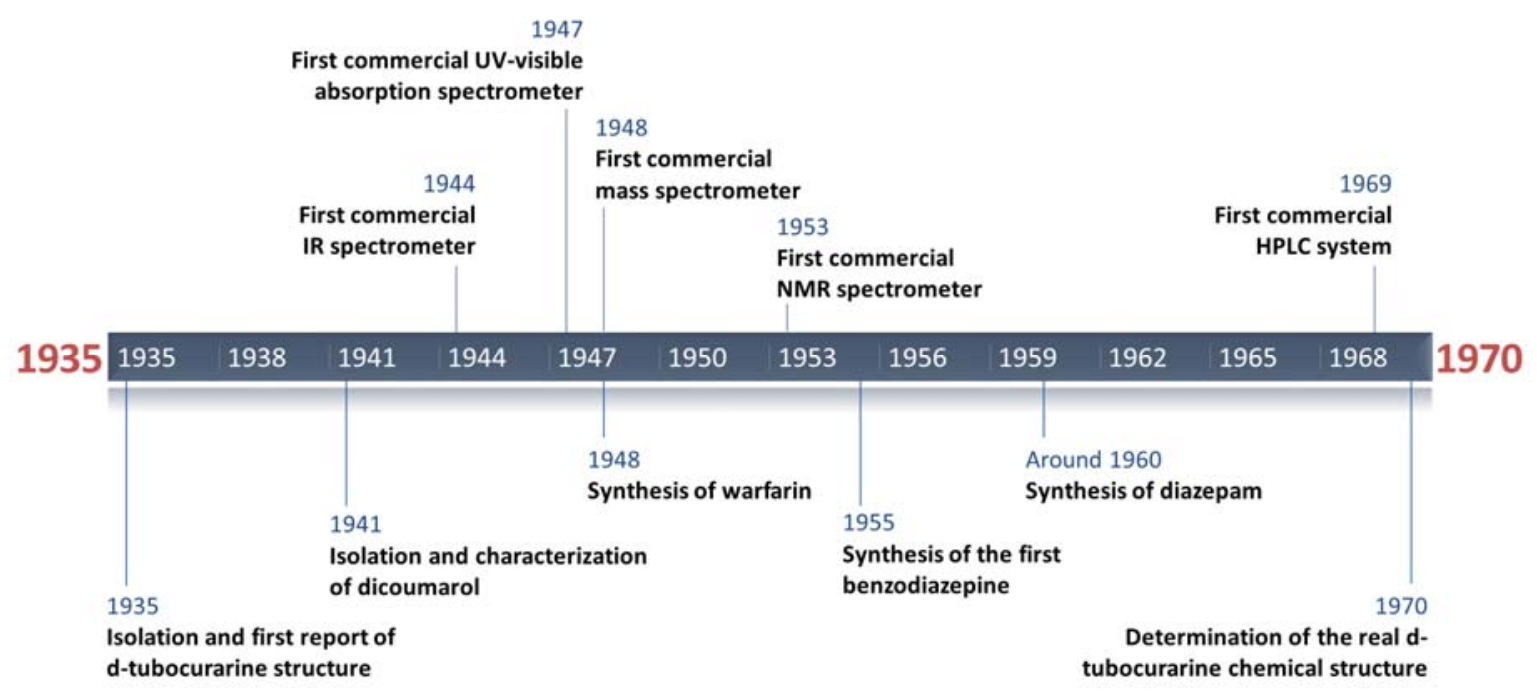

Figure 1. Timeline showing the introduction of the main techniques used for chemical analysis (top part of the timeline). Additionally, the timeline shows some of the key events that will be covered in the case studies (bottom part of the timeline).

Many current instrumental techniques that can be found in the laboratories were developed during the 20th century ${ }^{3}$ (Figure 1). These techniques include: high performance liquid 
chromatography (HPLC), nuclear magnetic resonance (NMR), Mass spectrometry (MS) or infrared (IR) spectroscopy, among others. Renowned chemical discoveries were developed in the 20th century before any of these techniques were available. Consequently, a set of lectures were designed which reviewed some of these chemical discoveries that were carried out without the assistance of modern instrumental analysis techniques.

As mentioned previously, this new set of lectures was designed using three case studies describing the discovery of three drugs/families of drugs: benzodiazepines, warfarin and neuromuscular blocking agents. These examples were carefully selected to stimulate the interest of the students in medicinal chemistry and chemical analysis. Moreover, the content of the lectures was used to reinforce the importance of using chemical knowledge to solve analytical problems. Finally, the case studies were used to introduce different approaches to drug discovery and to review the main analytical techniques described in previous modules. The present manuscript provides a brief description of the medicinal chemistry module where the new set of lectures are included. The rationale behind this pedagogical approach is strongly influenced by the profile of pharmacy students and this will be discussed in the next section of the present work. Subsequently, a brief description of the case studies will be provided, including the experiences of the lecturer while preparing and delivering the lectures. Finally, the opinion of the students about the new set of lectures are presented and discussed.

\section{Module overview and methods}

The three case studies that will be described in further sections were developed for pharmacy and pharmaceutical sciences students. This type of student does not show the same interest in chemistry than conventional chemistry students and this pedagogical approach is developed with this set of students in mind. The lectures were included in a module called "Drug design and pharmaceutical analysis". This is a $3^{\text {rd }}$ year module that has two main learning outcomes. The first main learning outcome is for the students to understand conventional (classical) and modern approaches to drug design and development. The second learning outcome is to understand and apply analytical techniques and related methodologies for the identification and/or quantification of drugs in various matrices. The first semester is focused on applied pharmaceutical analysis while the second semester is focused on drug design. The case study lectures described in this paper were delivered to the students at the end of the first semester in two 1 hour lectures. Prior to the delivery of these case study lectures, a set of three one hour lectures was delivered to the students reminding them of the main analytical techniques learned during the previous year and emphasizing the possible applications of each technique. Consequently, the case studies were used as a way to apply to real life situations all the previously acquired knowledge about analytical techniques. 
All the case studies contained two main parts, the history section and the technical section. The history section was prepared to give context to the case study. For this purpose, a few PowerPoint slides were designed to introduce: (i) the historical situation of every drug discovery, (ii) the scientist behind the discovery and (iii) the importance/impact of the discovery. The historical context used to prepare these case studies can be found in the supporting information with the appropriate references. The content presented in this section is important as it will contribute to the stimulation of students' interest in the topic. This sets the scenario for the next part of the case study that is the technical part.

The technical part of the case studies described the main technical challenge faced during drug discovery when trying to analyze the new molecule/s. Additionally, the methods used to analyze the new molecules were briefly described. At this point, the students were asked some questions about the modern methods of analyzing those drugs. This content can be found in the next sections of the work presented here. The facts were presented to the students in a conventional way (teacher-centred teaching) but during the technical section of the case studies some exercises were included in the lectures. The students were asked to complete them within the classroom in 10-15 minutes and the possible answers were discussed. The case studies were focused on highlighting different ways to analyze drugs during drug discovery.

After delivering the lectures, a questionnaire was administered to the students to obtain their opinions about the inclusion of this new material. The lectures were delivered to $3^{\text {rd }}$ year pharmacy and pharmaceutical sciences students in October 2017. The students could provide feedback in the questionnaire about the lectures. The comments of the students were classified as positive, negative or mixed. The comments describing satisfaction after the lectures were classified as positive. On the other hand, comments describing dissatisfaction were classified as negative. Finally, the comments that could not be classified in any of the previous categories were labelled as mixed. The total number of students in the lectures was 55 (48 pharmacy students and 7 pharmaceutical sciences students) and the module name was: Drug Design/Pharmaceutical Analysis (PMY3082).

\section{Justification of the approach}

The chosen case studies were unique and novel as they did not adhere to the conventional approach to drug discovery but rather involved a certain degree of creativity and originality as these scientists sought to overcome the technical limitations of their analytical methods. These case studies were chosen because it was believed that their originality and novelty would grab 
the attention of the students and motivate them to engage with the chemistry concepts delivered in the course. It has been widely accepted that we remember stories longer than facts $^{4-6}$. Furthermore, Brown and Atkins described in their book 'Effective Teaching in Higher Education': "A narrative approach interleaved with a problem-centred structure is likely to reveal your own enthusiasm for a topic-itself a motivator-and play on the intellectual curiosity of the audience" ${ }^{\prime \prime}$. The presentation of historical examples in chemistry classes has been extensively described as a successful pedagogical approach by a wide variety of authors $^{8-13}$. Due to the emphasis on chemical analysis in the case study lectures, they provided a good example of the possible real applications of the analytical techniques studied during the previous lectures and in previous years. Additionally, the lectures introduced two of the main strategies used in drug development: pure synthetic chemistry and extraction from natural sources. As one of the main objectives of the module is to study drug design, these case studies also fit nicely into overall degree program as it gave an introduction to drug discovery which is covered in detail during the second semester. Finally, the active learning exercises the students engaged in are similar to the exercises that are included in the summative assessment of the module. Therefore, this approached helped the students to recap the previously delivered content and made the assessment process more transparent.

Three case studies were chosen with the following objectives in mind:

- Stimulate the interest of the students for the topic.

- Demonstrate to students how chemical knowledge will help them to solve problems they are likely to encountered when working as a chemical analyst.

- Introduce some examples of conventional approaches for drug discovery.

- Review material covered in the theoretical classes by demonstrating how this theoretical knowledge has been used in real life examples to make novel discoveries.

As mentioned previously, the lectures were designed as review sessions for all the theory covered before. Active learning elements were added to the lectures as small exercises related with the content delivered to reinforce student understanding of the topics. Several authors have described that the inclusion of active learning elements in the lectures increases student understanding and performance in science, engineering, and mathematics ${ }^{14}, 15$. Finally, the lectures were developed to be in line with the development of an integrated curriculum for pharmacy students. Pharmacy curriculum integration is important to produce graduates who have the capacity to apply their knowledge to a range of complex problems ${ }^{16}$. In this case, the lectures presented here were designed to integrate the analytical chemistry into applied cases of drug discovery. 


\section{Case Studies}

In the next sections, the main content of the case studies will be described. Additionally, the experiences/views of the lecturer while preparing and delivering the lectures are outlined. As mentioned previously, the three case studies were separated in two groups: the first case study was focused on the discovery of benzodiazepines to emphasize the importance of chemical synthesis in drug discovery. The other two case studies were delivered together. They described how warfarin and neuromuscular blocking drugs were developed using molecules extracted from natural sources as inspiration.

Case Study I: Drug discovery through chemical synthesis. The Benzodiazepines Story. The discovery of benzodiazepines was accomplished following a pure synthetic approach. In addition to introducing the chemical synthesis approach for drug discovery, the inclusion of this case study also allowed me to discuss several issues related to molecule identification and structure determination of molecules.

Benzodiazepines are a group of molecules with a wide range of actions: sedative, hypnotic, anxiolytic, anticonvulsant and muscle relaxant ${ }^{17}$. In the late 1970 s, benzodiazepines become the most commonly prescribed drugs in the world ${ }^{17}$. Consequently, and due to its enormous impact in society, this case study should be of particular interest to chemistry and pharmacy students. The discovery of this type of drug involves a certain degree of serendipity as, after years of unsuccessful work, the first type of benzodiazepine was discovered while cleaning the laboratory just before finishing the research project. The unconventional research program, with a "last minute" discovery, in combination with the enormous relevance of benzodiazepines in the pharmaceutical field makes this case study a good candidate to stimulate the attention of the students. All the information about the discovery of this type of molecule that was presented to the students can be seen in the Supporting Information. In addition, to demonstrate the importance of chemical synthesis and the impact of a compound in society, the benzodiazepine example can be used to highlight to chemistry and pharmacy students that technical limitations can be overcome with creative solutions.

The second part of the case study focused on chemical analysis. One of the key learning outcomes of the module is to show how all the previously acquired knowledge about chemical analysis can be applied to real case examples. Accordingly, the students were shown some analytical challenges that arose during benzodiazepine discovery. In his article, 'The Benzodiazepine Story', Dr. Leo Sternbach described that the initial structure of chlordiazepoxide, the first benzodiazepine, was wrongly established ${ }^{17}$. During the synthesis of this molecule (Figure 2A), Sternbach and co-workers did not have access to modern 
analytical techniques ${ }^{17}$. By having a look at Figure 1 it is noticeable that NMR and mass spectrometry were commercially available when benzodiazepines were discovered. However, these powerful techniques were not optimized for the analysis of organic molecules and Sternbach and co-workers did not have access to them at that time ${ }^{17}$. Due to the technical limitations at the time, the research group started a complex process of breaking the molecule and analysing its fragments to try to obtain the correct structure of the molecule (Figure 2B).

A<smiles>NNCc1nc2ccc(Cl)cc2c(-c2ccccc2)[n+]1[O-]</smiles>

B<smiles>CNC1=Nc2ccc(Cl)cc2C(c2ccccc2)=[N+]([O-])C1</smiles><smiles>CNCc1nc2ccc(Cl)cc2c(-c2ccccc2)[n+]1[O-]</smiles><smiles>CN=CC(=CC=CCl)c1ccccc1</smiles><smiles>NCC(=O)O</smiles>

Figure 2. One of the synthetic steps used to obtain chlordiazepoxide. Compound 1 was erroneously determined (A). Fragmentation procedure followed by Sternbach and co-workers to determine the structure of chlordiazepoxide (B).

Sternbach solved this problem with a time consuming but effective approach. However, this approach can be easily avoided nowadays as different techniques can be used to determine the chemical structure of chlordiazepoxide. Subsequently, some active learning elements were introduced in the lecture. Some exercises were presented to the students (Box 1) and 10-15 minutes were given to them in order to think about the answers. When the students completed the exercise, we discussed the answers. As described previously in the lecture, 
NMR will be one of the recommended techniques to ascertain the structure of chlordiazepoxide. Therefore, the first exercise revolved around the structure of the erroneous chlordiazepoxide and the real molecule using two ${ }^{1} \mathrm{H}-\mathrm{NMR}$ spectra generated for both structures. The students were told to use their previous knowledge to associate the structure with the corresponding spectrum. Both spectra are similar however spectrum A shows a peak at around $2.2 \mathrm{ppm}$ that can be assigned to the set $\mathrm{Hs}$ marked with an asterisk in the molecule. A similar peak can be seen in spectrum B but at around 3 ppm. Spectrum B correspond to the real chlordiazepoxide as in this case a double bond is closer to this set of Hs that yields at displacement of the peak at higher chemical shift values. This exercise was used as a reminder of how to interpret the information from NMR spectra and to demonstrate how it can be used in a real situation to establish the structure of an unknown molecule.

Box 1. Questions proposed to the students during the benzodiazepines lecture.

Question 1. Associate the NMR spectra with the corresponding chemical structure<smiles>[CH2]NCc1nc2ccc(Cl)cc2c(-c2ccc(OCC)cc2)[n+]1[O-]</smiles><smiles>[CH2+]NC1=Nc2ccc(Cl)cc2C(c2ccc(OC)cc2)=[N+]([O-])C1</smiles>

A
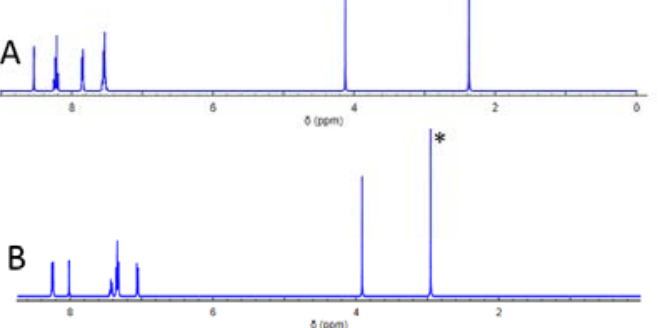

Question 2. Describe the main differences in the analysis of these compounds using the selected technique

a) FTIR for chlordiazepoxide and diazepam analysis

b) H-NMR for oxazepam and diazepam analysis

c) Mass Spectrometry for oxazepam and diazepam analysis<smiles>CNC1=Nc2ccc(Cl)cc2C(c2ccccc2)=C(O)C1</smiles><smiles>CN1C(=O)CN=C(c2ccccc2)c2cc(Cl)ccc21</smiles><smiles>O=C1Nc2ccc(Cl)cc2C(c2ccccc2)=NC1O</smiles>

When trying to establish the structure of a synthetic molecule, the analyst can predict the possible structure of the synthesized product. Accordingly, this example is a more realistic 
approach than the examples studied during previous academic years in which the students had been asked to build the structure of a totally unknown molecule using NMR spectra.

The main analytical challenge encountered during benzodiazepines discovery was to establish the chemical structure of chlordizepoxide. Therefore, this was a good moment to make the students reflect on other techniques that can also be used for the identification of chemical compounds. The second exercise involved refreshing their knowledge of the main principles of FTIR, mass spectrometry and NMR. The main differences between chlordiazepoxide and diazepam that will be observed using FTIR is the carbonyl group in diazepam that will be clearly observed at around $1600-1700 \mathrm{~cm}^{-1}$. On the other hand, the main difference between oxazepam and diazepam that will be observed during an ${ }^{1} \mathrm{H}-\mathrm{NMR}$ analysis is the observation of a peak attributed to the $\mathrm{Hs}$ in the methylene group attached to the $\mathrm{N}$ in diazepam. This peak will not be present in the ${ }^{1} \mathrm{H}-\mathrm{NMR}$ spectrum of oxazepam. If both molecules were analyzed using mass spectrometry, the obtained molecular weight for each molecule will be different. Additionally, diazepam will show a fragment at around $15 \mathrm{~m} / \mathrm{z}$ due to the previously mentioned methylene group.

This highlights how it took years for Sternbach and his team to break down the module but that with modern day chemical developments and technological innovations, this task can now be completed in days. In addition to this, the United Nations Office on Drugs and Crime guide for the analysis of drugs was presented to the students ${ }^{18}$, which list quick and standardized analytical methods for analysing benzodiazepines in the present day. With this information the student can easily compare the methods standardized for benzodiazepine identification with the methods that had been proposed by the students during the exercises.

This case study lent itself to the introduction of a practical scenario that allowed students to see the power and utility of structural determination techniques. Pharmacy students sometimes struggle to understand the importance of techniques of structural determination. These students need to understand how these techniques can be applied to drug discovery/development. By using integrated cases that demonstrate the importance of these techniques in drug discovery, the importance of these techniques is emphasized.

Case Studies II and III: Drug discovery through extraction of natural products. The warfarin and neuromuscular blocking drugs stories.

The second and third case studies covered examples of drug discoveries accomplished after extracting active molecules from natural sources: warfarin and neuromuscular blocking drugs. It is important to note that the in both cases the final molecules were synthesized not extracted. 
However, the drug design was accomplished with the information obtained from active compounds that were extracted from natural sources. The two examples selected are highly relevant to pharmacy students as both types of drugs are still used nowadays. Warfarin is used to prevent the formation of blood clots in the blood vessels and is the most widely used anticoagulant in the world ${ }^{19}$. On the other hand, neuromuscular blocking drugs are required for general anaesthesia ${ }^{20,21}$.

It is important to note that the selected examples of drug delivery were unconventional due to the circumstances leading to the discovery of the natural precursors of the final drug molecules. The precursor of warfarin was found in sweet clover hay after causing the death of multiple cattle from internal bleeding. On the other hand, the precursor of neuromuscular blocking drugs came from the amazon rainforest, as it was used by the natives for hunting. Therefore, these examples had the potential to stimulate the students' interest in this subject. The complete stories behind the discovery of both drugs can be found in the supporting information. Both examples are similar in their conception so, for reasons of space, they were discussed together.

The extraction of the precursors of both types of drugs was a long procedure. A precursor of warfarin, dicoumarol (Figure 3), was found in spoiled sweet clover hay in Wisconsin during the 1940s (USA). The extraction and identification of this molecule took 6 years of work. Long extraction protocols and rudimentary analytical procedures were used to determine the chemical structure of the molecule. A concentration and isolation process was developed and contained 16 steps $^{22-24}$ (Figure S6, Supporting Information). To determine the structure of the molecule, Link et al. used classical techniques based on chemical reactions rather than using instrumental techniques that were not then available (Figure 1). In a similar way, the precursor of the neuromuscular blocking, d-tubocurarine, agents was isolated for the first time in 1935 from a sample of curare, a poison used for hunting by South/central America natives ${ }^{20}$. The procedures developed by the researchers were time consuming and not really efficient. For example in the warfarin case, after stablishing the structure of dicoumarol, the last step was to prepare a synthetic version of these molecule and compare its anticoagulant activity with the one of the extracted molecule to confirm the obtained result ${ }^{22}$. 


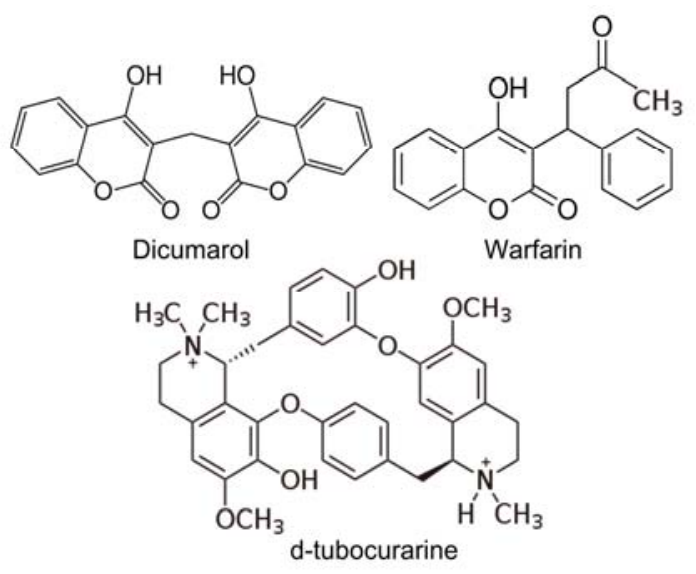

Figure 3. Structure of dicumarol, warfarin and d-tubocurarine.

In contrast, currently it is quite simple to isolate and analyze plant extracts similar to warfarin or coumarin. In the lecture, two examples were presented to the students. However, before describing any of these methods a fictional situation was proposed to the students: Imagine that you work for a company that requested the amount of dicoumarol in a sample of spoiled sweet clover hay to be quantified. What procedure would you follow? What techniques would you use? The students were given between 5-10 minutes to think about this. The main analytical technique that should be used is a chromatographic method as dicoumarol should be separated from the other compounds before it can be analyzed. This was a good example to use to introduce real life uses of HPLC. Before continuing with the lecture, we briefly discussed the main analytical approach that could be used to overcome this problem. The students soon realized that a plant sample will not only contain the desired molecule but multiple compounds that can interfere in a conventional analysis. Therefore, the majority of the students were convinced of the need of using HPLC for this type of analysis. This idea was reinforced in the neuromuscular blocking drug case study as another exercise of the use of HPLC was proposed to the students (see supporting information) but in this case they should provide details of how they will develop a method to quantify several anticancer compounds in a sample from natural origin.

As a real example of how HPLC can be used to separate and analyze samples from natural origins, a semi-preparative HPLC method for the isolation of warfarin and coumarin-like molecules from a medicinal plant, Murraya paniculata was presented ${ }^{25}$. The isolated molecules were characterized by means of MS. Next, the isolated compounds were tested as chemopreventive agents for metastatic cancer in colon cancer cell lines. It is noticeably quicker and easier than the process described by Link to isolate dicoumarol as it only contains a few extraction steps and a HPLC process. The second example was a paper published by 
Wang et al. which described a HPLC coupled with MS for the simultaneous analysis of coumarin in plant extracts ${ }^{26}$. In this case, with a single analysis a wide variety of coumarin derivatives can be determined. These two examples are illustrative of how the use of chromatography will speed up isolation processes. Additionally, in these two works the use of MS can be seen as a valuable tool to determine the structure of unknown molecules. The examples of HPLC use presented to the students highlighted how chromatography can be coupled with techniques such as MS to obtain information about the structure of the molecules. Consequently, this reinforce the idea that HPLC can be used to quantify the amount of a compound within a sample and to obtain structural information about unknown samples.

As described before, when isolating molecules for the first time their chemical structure should be established. Consequently, a few exercises related to establishing the proper chemical structure of extracted molecules were introduced (see Box 2). The first question shows FTIR, ${ }^{1} \mathrm{H}-\mathrm{NMR}$ and mass spec spectra for dicoumarol. In this exercise, the students should identify that the molecular weight obtained (mass spec) can only be attributed to dicoumarol and not warfarin. Moreover, the ${ }^{1} \mathrm{H}-\mathrm{NMR}$ showed the typical aromatic signals that should be present in both molecules and an extra peak around $4 \mathrm{ppm}$. Warfarin should show at least 3 signals in addition to the aromatic peaks. Subsequently, the answer to question 1 is dicoumarol. In the same way, during the neuromuscular blocking agents case study, a ${ }^{1} \mathrm{H}-\mathrm{NMR}$ exercise linked with d-tubocurarine story was proposed to the students. When the structure of this molecule was first established an incorrect structure was assigned to the molecule (see supporting information). Accordingly, a ${ }^{1} \mathrm{H}-\mathrm{NMR}$ spectra for correctly assigned and incorrectly assigned d-tubocurarine molecules were generated and presented to the students (Box 2: Question 2). It can be seen that the extra methylene group can be observed in the ${ }^{1} \mathrm{H}-\mathrm{NMR}$ for the erroneous molecule as two peaks at around $3 \mathrm{ppm}$. This is consistent with the ${ }^{1} \mathrm{H}-\mathrm{NMR}$ peak assignation found in the literature for d-tubocurarine ${ }^{27}$. This exercise demonstrate to the students how nuclear magnetic resonance will quickly distinguish between the wrongly established molecule and the real one. This is another good example of how modern techniques can be used to determine the structure of a molecule accurately and quickly in comparison to the methods that were used in the past. Interestingly, the real structure of the molecule was determined 35 years later in 1970 (Figure 3) and NMR was used for this purpose $^{28}$.

During the warfarin lecture, another question was proposed to the students (Box 2: Question 3). This question can have multiple answers and it was designed to start a discussion about what will be the best technique in terms of sensitivity. This question allows the students to reflect about the chemical structure and how it is related with the use of certain techniques. 
For example, due to the rigidity and double bond conjugation in warfarin structure, fluorescence will be a good option in terms of sensitivity. On the other hand, aspirin did not present that characteristics and, subsequently, in this case UV-visible spectroscopy would be a better option.

Box 2: Questions proposed to the students during the warfarin and neuromuscular blocking drugs lectures. FTIR and Mass Spec spectra were obtained from NIST Chemistry WebBook ${ }^{29}$.
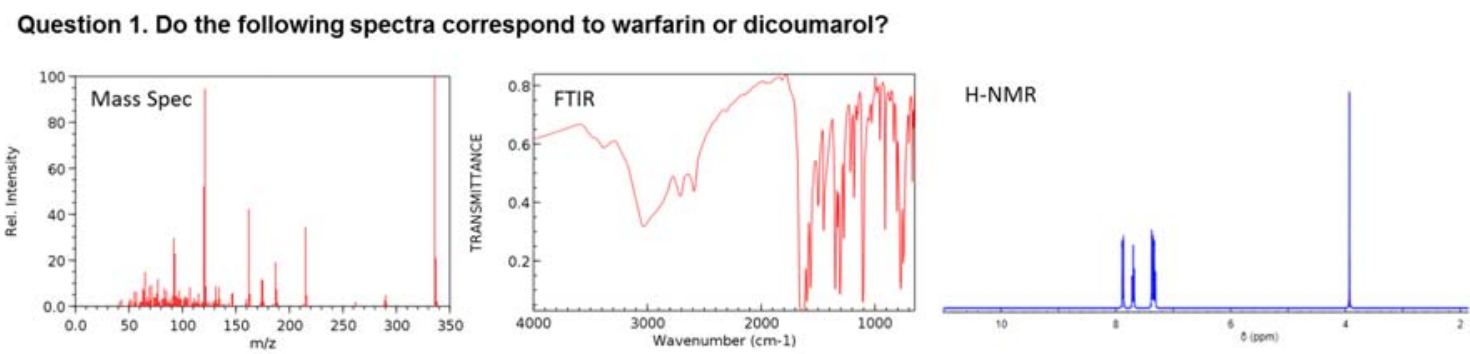

Question 2. Which of the following NMR spectra belongs to the real d-tubocurarine molecule?
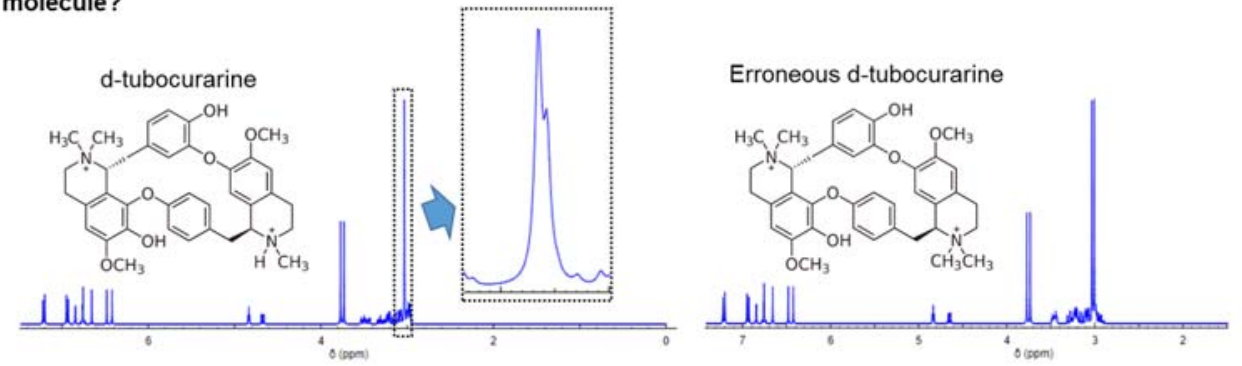

Question 3. Imagine that you have to design a method to quantify these two compounds used to treat thromboembolism.

What techniques will you use?<smiles>CC(=O)Oc1ccccc1C(=O)O</smiles><smiles>CC(=O)CC(c1ccccc1)c1c(O)c2ccccc2oc1=O</smiles>

As mentioned previously, the inclusion of clinically relevant aspects of the topic is crucial for pharmacy students. For this reason, the importance of developing sensible methods to quantify warfarin levels in plasma for patients was discussed during the warfarin case study. The monitoring of patients prescribed with warfarin is really important and analytical techniques, such as HPLC, are key to be able to quantify the levels of this drug in plasma.

\section{Questionnaire Results.}

The study was approved by the Queen's University Belfast School of Pharmacy Ethics Committee (Ref: 021PMY2017). The three described examples were delivered to $3^{\text {rd }}$ year students of pharmacy and pharmaceutical sciences degrees in a chemistry module. After 
finishing the lecture series, a questionnaire was given to the students to evaluate their opinions about the content of the lectures. The number of students that completed and returned the questionnaire was 55. A Likert scale was used to measure the answers.

Figure 4 shows the results obtained after administering the questionnaire to the students during the lectures delivered during the 2017-2018 academic year. The general conclusion is that at least $60 \%$ of the students answered positively to all the questions (agreed or strongly agreed). Showing that the majority of the class enjoyed the content and found the lectures engaging and interesting. Generally, less than $16 \%$ of the students provided negative feedback (disagree or strongly disagree) about the lectures.

The first three questions showed that the majority of the class believed that knowing the history behind science is important, allowing a better understanding of the science and enriching their education. Despite having low negative feedback in these questions, a proportion of the class (lower than 16\%) stated they were indifferent to these examples. This demonstrates that not everybody is interested in history and this should be taken into account when using this approach. Conducting a survey in class before preparing this type of lectures can be a good approach.

The last two questions showed that at least $75 \%$ of the students found that the selected approach stimulated their interest in the subject and that the case studies helped with the understanding of instrumental chemical analysis. These results show that the initial approach was successful as it improved their understanding and stimulated their interest, which was the main objectives of these lectures. 


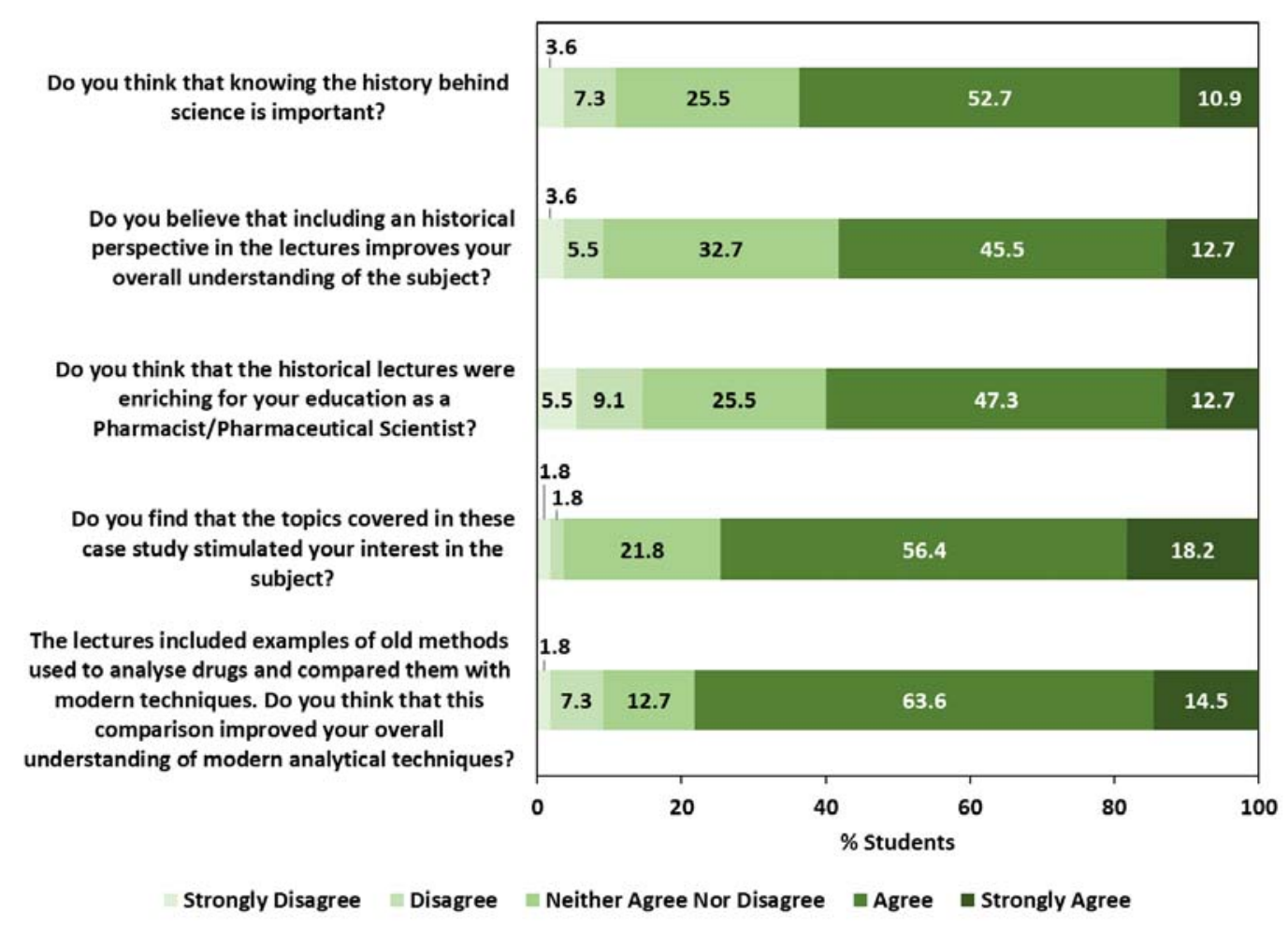

Figure 4. Results of the questionnaires administered to the students. The number of students that answered the questionnaire was 55 .

The questionnaire had a section to allow the students to give their opinion on the lectures as well. The comments were classified as positive, negative and mixed. A summary of these comments and exemplar comments can be found in the supporting information (Table S1). Some of them described that the inclusion of the historical cases made the lectures more engaging. Only a few negative comments were obtained. These students stated they did not find the lectures engaging as they were not really interested in the topic and/or the historical perspective. Some of these students stated that the approach was engaging but they did not find the analytical chemistry subject engaging. The negative feedback opens the door to improve this approach. It can be established that the majority of the class find these case studies interesting and appealing. However, a proportion of the class was indifferent. The results demonstrate that the strategy was successful as the majority of the class found the lectures engaging and the topics stimulated their interest in the subject.

Similarly, in the previous academic year (2016-2017), the same case studies were delivered to the students. However, the method was slightly different as the lectures did not contain active learning exercises or a clinical emphasis. The views of the students about the case studies can be found in the Supporting information section (Tables S1 and S2). 
As explained before, the class contained mainly pharmacy students and some pharmaceutical sciences students. The latter are focused predominately on the industrial aspects of pharmacy. However, pharmacy students have a broader career path, including community/clinical pharmacy and industrial pharmacy. Clinical/community pharmacists tend not to use chemistry in their daily work, instead primarily dealing with patients. On the other hand, industrial pharmacists need to use chemistry every day. Subsequently, these case studies should be adapted to fit the interest of the audience according to their future careers.

\section{Conclusions}

A set of two lectures describing historical cases of drug discovery were implemented in an analytical chemistry module for pharmacy students. The cases contained three examples of drug discovery under unusual circumstances to stimulate the interest of the students. For each drug, the methods used by the researchers to analyze the drugs were described and compared with modern techniques. In this way, the students were made aware of modern improvements in analytical techniques and the importance of using their chemical knowledge to overcome problems during analysis. Finally, the students completed a survey describing their opinions about the implementation of these lectures in the module. The overall results were positive and the comments obtained suggested that the initial objectives of including such case studies in the lectures were fulfilled. The results also indicate that it is important to include examples of chemical analysis which are relevant to the future careers of students in order to ensure that they find such examples interesting and relevant.

\section{Associated content}

\section{Supporting Information}

The Supporting Information is available on the ACS Publications website at DOI: 10.1021/acs.jchemed.XXXXXXX.

The supporting information includes the following content:

- Material describing the history around the three case studies.

- Student's opinion about the drug discovery case studies 2016.

\section{Acknowledgments}

The author would like to thank Prof. R.F. Donnelly and Dr. M. Butler (Queen's University Belfast) for their invaluable assistance during the preparation of the manuscript. For the loan of images included in the paper the author thanks: Roche Historical Collection and Archive, University of Wisconsin-Madison Archives, American Museum of Natural History, Geoffrey 
Kaye Museum of Anaesthetic History and Scientific Reports journal. Finally, Prof. A. Monge (Universidad de Navarra) is acknowledged for discovering to the author some of the examples described in this manuscript during his Pharmaceutical Chemistry classes.

\section{References}

1. Alsharif, N. Z.; Galt, K. A.; Mehanna, A.; Chapman, R.; Ogunbadeniyi, A. M. Instructional Model to Teach Clinically Relevant Medicinal Chemistry. Am. J. Pharm. Educ. 2006, 70, 91.

2. Chapman, R. L. Patient-related case-studies in medicinal chemistry. Am. J. Pharm. Educ. 1994, 58, 446-450.

3. Thomas, N. C. The early history of spectroscopy. J. Chem. Educ. 1991, 68, 631-634.

4. Santovec, M. L. 'Tell Me a Story': Their Power to Teach and Recall. Women in Higher Education 2012, 21, 25-25.

5. Lawrence, R. L.; Paige, D. S. What Our Ancestors Knew: Teaching and Learning Through Storytelling. New Dir. Adult Contin. Educ. 2016, 2016, 63-72.

6. Herreid, C. F. Start with a Story: The Case Study Method of Teaching College Science; NSTA Press: Arlington, 2007.

7. Brown, G.; Atkins, M. Effective Teaching in Higher Education; Routledge: Bristol, 1988.

8. Gauld, C. History of science, individual development and science teaching. Res. Sci. Ed. 1991, 21, 133-140.

9. Matthews, M. R. A role for history and philosophy in science teaching. Educational Philosophy and Theory 1988, 20, 67-81.

10. Olsson, K. A.; Balgopal, M. M.; Levinger, N. E. How Did We Get Here? Teaching Chemistry with a Historical Perspective. J. Chem. Educ. 2015, 92, 1773-1776.

11. Debus, A. G. The relationship of science-history and history of science. J. Chem. Educ. $1971,48,804$.

12. Zaragoza, C.; Fernàndez-Novell, J. M. More history of chemistry, more interest in science. In 4th International Conference of the European Society for the History of Science : Barcelona, 18-20 November 2010 : book of abstracts. Terreu i Gascon, M., Ed.; Institut d'Estudis Catalans: Barcelona, 2010; pp 125-131.

13. Irwin, A. R. Historical case studies: Teaching the nature of science in context. Sci. Educ. 2000, 84, 5-26.

14. Freeman, S.; Eddy, S. L.; McDonough, M.; Smith, M. K.; Okoroafor, N.; Jordt, H.; Wenderoth, M. P. Active learning increases student performance in science, engineering, and mathematics. Proc. Natl. Acad. Sci. U. S. A. 2014, 111, 8410-8415. 
15. Singer, S.; Smith, K. A. Discipline-Based Education Research: Understanding and Improving Learning in Undergraduate Science and Engineering. J. Eng. Educ. 2013, 102, 468-471.

16. Husband, A. K.; Todd, A.; Fulton, J. Integrating Science and Practice in Pharmacy Curricula. Am. J. Pharm. Educ. 2013, 78, 63.

17. Sternbach, L. H. The. J. Med. Chem. 1979, 22, 1-7.

18. United Nations. Recommended Methods for the Detection and Assay of Barbiturates and Benzodiazepines in Biological Specimens: Manual for use by National Laboratories; United Nations Publications: Vienna, 1997.

19. Wardrop, D.; Keeling, D. The story of the discovery of heparin and warfarin. Br. J. Haematol. 2008, 141, 757-763.

20. Caldwell, J. E. A History of Neuromuscular Block and Its Antagonism. In The Wondrous Story of Anesthesia; Eger, I. I., Saidman, L. J., Westhorpe, R. N., Eds.; Springer: New York, 2014; pp 671-691.

21. Raghavendra, T. Neuromuscular blocking drugs: discovery and development. J. R. Soc. Med. 2002, 95, 363-7.

22. Stahmann, M. A.; Huebner, C. F.; Link, K. P. Studies on the hemorrhagic sweet clover disease V. Identification and synthesis of the hemorrhagic agent. J. Biol. Chem. 1941, 138, 513-527.

23. Campbell, H. A.; Roberts, W. L.; Smith, W. K.; Link, K. P. Studies on the hemorrhagic sweet clover disease I. The preparation of hemorrhagic concentrates. J. Biol. Chem. 1940, $136,47-55$.

24. Campbell, H. A.; Link, K. P. Studies on the Hemorrhagic Sweet Clover Disease IV. The Isolation and Crystallization of the Hemorrhagic Agent. J. Biol. Chem. 1941, 138, 21-33.

25. Shao, J.; Zhou, S.; Jiang, Z.; Chi, T.; Ma, J.; Kuo, M.; Lee, A. Y. L.; Jia, L. Warfarin and coumarin-like Murraya paniculata extract down-regulate EpCAM-mediated cell adhesion: individual components versus mixture for studying botanical metastatic chemopreventives. Sci. Rep. 2016, 6, 30549.

26. Wang, B.; Liu, X.; Zhou, A.; Meng, M.; Li, Q. Simultaneous analysis of coumarin derivatives in extracts of Radix Angelicae pubescentis (Duhuo) by HPLC-DAD-ESI-MSn technique. Anal. Methods 2014, 6, 7996-8002.

27. Fraenkel, Y.; Gershoni, J. M.; Navon, G. NMR Analysis Reveals a Positively Charged Hydrophobic Domain as a Common Motif to Bound Acetylcholine and d-Tubocurarine. Biochemistry 1994, 33, 644-650.

28. Everett, A. J.; Lowe, L. A.; Wilkinson, S. Revision of the structures of (+)-tubocurarine chloride and (+)-chondrocurine. J. Chem. Soc. D 1970, 0, 1020.

29. National Institute of Standards and Technology. NIST Chemistry WebBook, NIST Standard Reference Database Number 69. https://webbook.nist.gov/chemistry/ (accessed June, 2018). 


\title{
SUPPORTING INFORMATION - How can sedatives, spoiled sweet clover hay and plants
} from the Amazon rainforest be incorporated into a pharmaceutical chemistry course?

\author{
Eneko Larrañeta*
}

School of Pharmacy, Queen's University Belfast, 97 Lisburn Road, Belfast, BT9 7BL, UK.

\section{Material used to prepare the case studies}

\subsection{The Benzodiazepines Story}

Benzodiazepines were first synthesized by Dr. Leo Sternbach while working for the Chemical Research Department of Hoffman La Roche (New Jersey, USA) ${ }^{1}$. Leo Sternbach was born in Croatia in 1908 in an upper middle class Jewish family. He moved to Poland in 1926 and there he attended to Jagiellonian University in Cracow. In 1929 he received his master's degree in pharmacy and three years later, his doctoral degree in organic chemistry. His main area of expertise was organic synthesis. After his Masters he left Poland and worked in different European countries. First he moved to Austria and subsequently to Switzerland. In 1940, during his time in Switzerland he starts working for Hoffman La-Roche a pharmaceutical company in a project centred on the synthesis of Vitamin B2, also known as riboflavin ${ }^{1}$. This Swiss company was well-known to hire Jews and foreigners and protect them from deportation to German labour camps ${ }^{1}$. Finally, in 1941, the company relocated Sternbach and his wife to his facilities in New Jersey, USA in order to guarantee their security. Sternbach worked on different projects for Hoffman La-Roche but his most prominent discovery there was the synthesis of benzodiazepines ${ }^{1}$.

In the mid-1950s Roche decided to embark in a new project centred on the synthesis of tranquilizers. Two approaches were considered: the synthesis of new compounds with unknown biological activity or the modification of pre-existing molecules. Sternbach and his team decided than the first approach was the most promising for them as they were mainly interested on pure synthetic bench work ${ }^{2}$. They established that the candidate molecule should be relatively unexplored, accessible, easy to modify and "likely" to present biological activity $^{2}$. In their search, Sternbach and his team decided that the benzheptoxdiazines seemed to be good candidates for this purpose ${ }^{2}$. Sternbach worked on the synthesis of this compounds before, during his postdoctoral research in Cracow. They start to synthesize different types of compounds and the project continued for years. Despite being successful in the chemical synthesis none of the products were biologically active. In 1957, the project was not giving the expected results. However, during a major laboratory cleaning a Sternbach co-worker found a few milligrams of a nice crystalline base and its hydrochloride that was synthesized 2 years 
earlier, this product was chlordiazepoxide ${ }^{2}$. The product was submitted for pharmacological testing. The results were surprising for the researchers, as they found that these synthetic compounds had sedative and tranquilizer activity. In fact, the new molecule showed better results, in the majority of the pharmacological animal tests, than the then most used tranquilizer and hypnotic, phenobarbital. Additionally, the product presented low toxicity. All these promising results suggested that they had found an ideal candidate. After completing more experiments, a patent was filed in May 1958 and, in July 1959, it was granted. After clinical testing, chlordiazepoxide was quickly introduced in the market in 1960 under the name of Librium ${ }^{\circledR 1,2}$. A picture of Sternbach and a model of chlordiazepoxide can be seen in Figure S1.
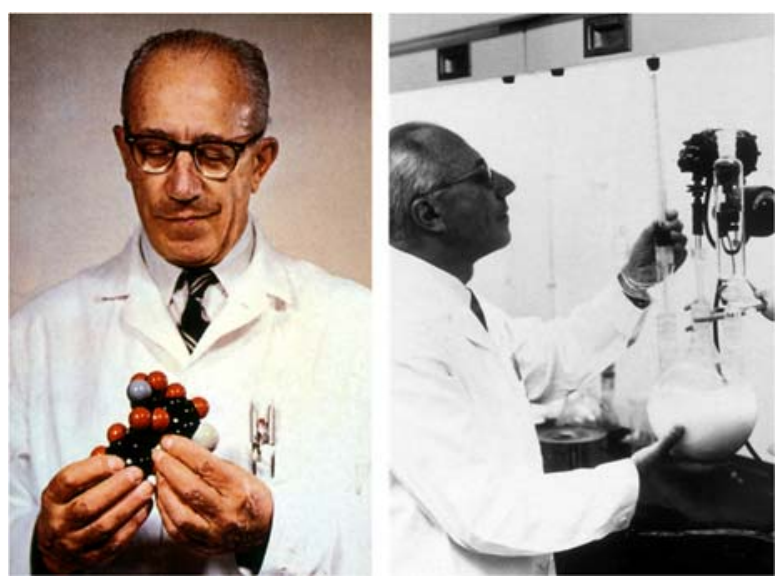

Figure S1. Leo H. Sternbach with a model of chlordiazepoxide molecule and working in the lab in 1960. Courtesy of the Roche Historical Collection and Archive.

During the next years, Sternbach and co-workers continued their work by synthesizing several derivatives of the initial molecule. Following chlordiazepoxide, diazepam was the next benzodiazepine commercialized by Hoffman-La Roche in under the brand name of Valium ${ }^{\circledR}$ in 1963. Subsequently more benzodiazepines were subsequently introduced to the market during the next years. Benzodiazepines become the most commonly prescribed drugs in the world by $1970 \mathrm{~s}^{1,2}$. Figure S2 shows the core structure of benzodiazepines and several benzodiazepines derivatives.

The discovery of this drug was a revolution. These molecules provide an alternative for anxiety disorders treatment with a greatly improved safety profile. Benzodiazepines replaced barbiturates ${ }^{3}$. Barbiturates were known to be dangerous in overdose, they caused addiction and presented troublesome side-effects ${ }^{3}$. Besides, benzodiazepines replaced other compounds that were used previously to treat anxiety included opium and alcohol ${ }^{3}$. However, an important factor that should be taken into account is that benzodiazepines should only be 
prescribed for short periods of time. During the $70 \mathrm{~s}$ and $80 \mathrm{~s}$ they were overprescribed generating tolerance and dependence ${ }^{3}$. Consequently, the prescription of this type of drugs has declined significantly since $1988^{3}$.<smiles>[R]c1ccc2c(c1)C(c1ccccc1[R7])=NCC(=[R])N2[R]</smiles>

Core structure of benzodiazepines
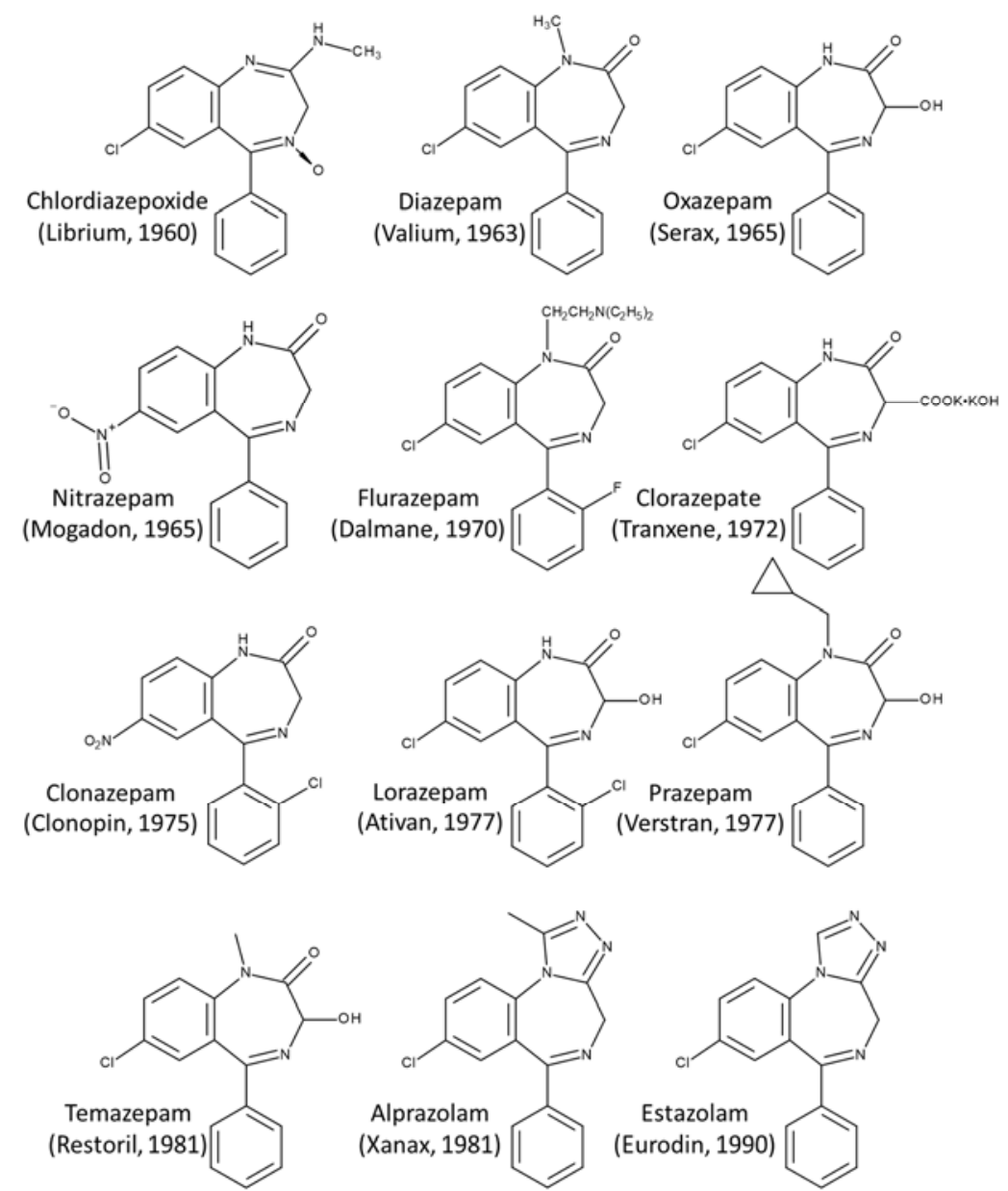

Figure S2. Core structure of benzodiazepines and several benzodiazepines derivatives marketed in the U.S. with their generic trade names and introduction dates.

In addition to show the importance of chemical synthesis and the impact of a compound in society, the benzodiazepine example can be used to show to chemistry or pharmacy students that technical limitations can be overcame with creative alternative solutions. During the synthesis of chlordiazepoxide, Sternbach and co-workers did not have access to modern techniques, such as MS or NMR ${ }^{2}$. Therefore, the structure of the chemical compounds was established by using more traditional methods. In his article the The Benzodiazepine Story, Sternbach described that the initial structure of chlordiazepoxide was wrongly established ${ }^{2}$. They found that after the chemical reaction of an intermediate compound with methylamine (Figure 2 main text) the UV and IR spectra of the resulting compound was totally different than 
the ones obtained for the initial reagents. They were expecting a totally new molecule but the compound was similar to previously synthesized molecules that were not pharmacologically active. Therefore, Sternbach and co-workers thought that the structure of the molecule was established correctly. At that time NMR or MS was not used to determine the structure of complex organic molecules so they used classical methods to ascertain the structure of chlordiazepoxide. For this purpose, they fractured Librium molecule and then and analyzed the fragments obtained. Figure 2 (main text) shows the fragmentation process. The first step was to remove the $\mathrm{N}$ oxide and subsequently they hydrolyzed the molecule in acidic conditions. In addition to IR and UV spectroscopies they could determine the elementary composition and molecular weight of the molecules. Finally, after analysing the fragments they established the correct structure of chlordiazepoxide.

\subsection{Warfarin, from rat poison to anticoagulant}

Warfarin is a molecule that prevents the formation of blood clots in the blood vessels. It was introduced as anticoagulant in the early 1950s and still is the most widely used anticoagulant in the world. The thorough work of a group of researchers, led by Karl Paul Link, at Wisconsin University (USA) lead to the discovery of this important molecule ${ }^{4}$.

The history behind the discovery of this molecule starts in the 1920s. During this decade in the prairies of Canada and the Northern Plains of America healthy cattle began dying unexpectedly of internal bleeding. The economic impact of this issue in those areas was enormous, as livestock was one of the main pillars of their economy. Besides, the problem was aggravated by the Great Depression. Soon it was apparent that the problem appeared more frequently when the cattle were fed with wet sweet clover hay. In this condition, hay became infected by moulds, such as Penicilliumnigricansand ${ }^{4}$. It was evident that these organisms seemed to play an important role in the disease process. Consequently, the main solution for the problem was to avoid mouldy sweet clover hay as foodstuff for cattle. Despite the advice, some farmers continued feeding the animals with the spoiled hay, as they did not believe this theory.

The first contact of Karl Paul Link with the clover problem was 10 years after the original outbreak $^{4}$. In 1933, a Wisconsin farmer desperate after losing so many animals brought to Link's office a can of milk filled with the unclotted blood from his animals ${ }^{4}$. This encounter with the farmer started a research project that ended with the discovery of Warfarin. The first step was to isolate the compound responsible for the cattle bleeding from the spoiled hay ${ }^{5-7}$. Links team developed a new in vitro clotting assay using plasma from rabbits and they started to 
develop a chemical fractionation of compounds present in the hay 4 . They worked intensely for 6 years between 1933 and 1939 until they obtained the anticoagulant substance ${ }^{4}$. The molecule behind the internal bleeding of the animals was dicoumarol ${ }^{7}$. The structure of this molecule was finally confirmed on the $1^{\text {st }}$ of April, 1940, when the research team prepares a synthetic dicoumarol and the properties of both, the synthetic and the isolated compound seemed to be identical ${ }^{4}$. The process that yielded this molecule was described too. The oxidation of natural coumarin present in sweet clover to 4-hydroxycoumarin is induced by bacterial action and two of these molecules finally are combined to form a bis-coumarin4. Additionally, in the early 1940s it was discovered that vitamin K reversed the effect of dicoumarol ${ }^{4}$.

In 1945 Link thought that it can be used as rodenticide do to its ability to kill animals from internal bleeding 4 . The main limitation of dicoumarol as rodenticide was that it acted too slowly for this purpose. Consequently, Link and his team started a project to synthesize different derivatives of the original molecule ${ }^{4}$. The synthetic program yielded 150 different molecules and the best candidate was number 42. It was called Warfarin after the initials of the organization that funded the research work: Wisconsin Alumni Research Foundation ${ }^{4}$. Figure S3 shows pictures of Karl Paul Link working in his lab during the warfarin discovery and a picture of him standing in front of a poster advertising warfarin as rodenticide.
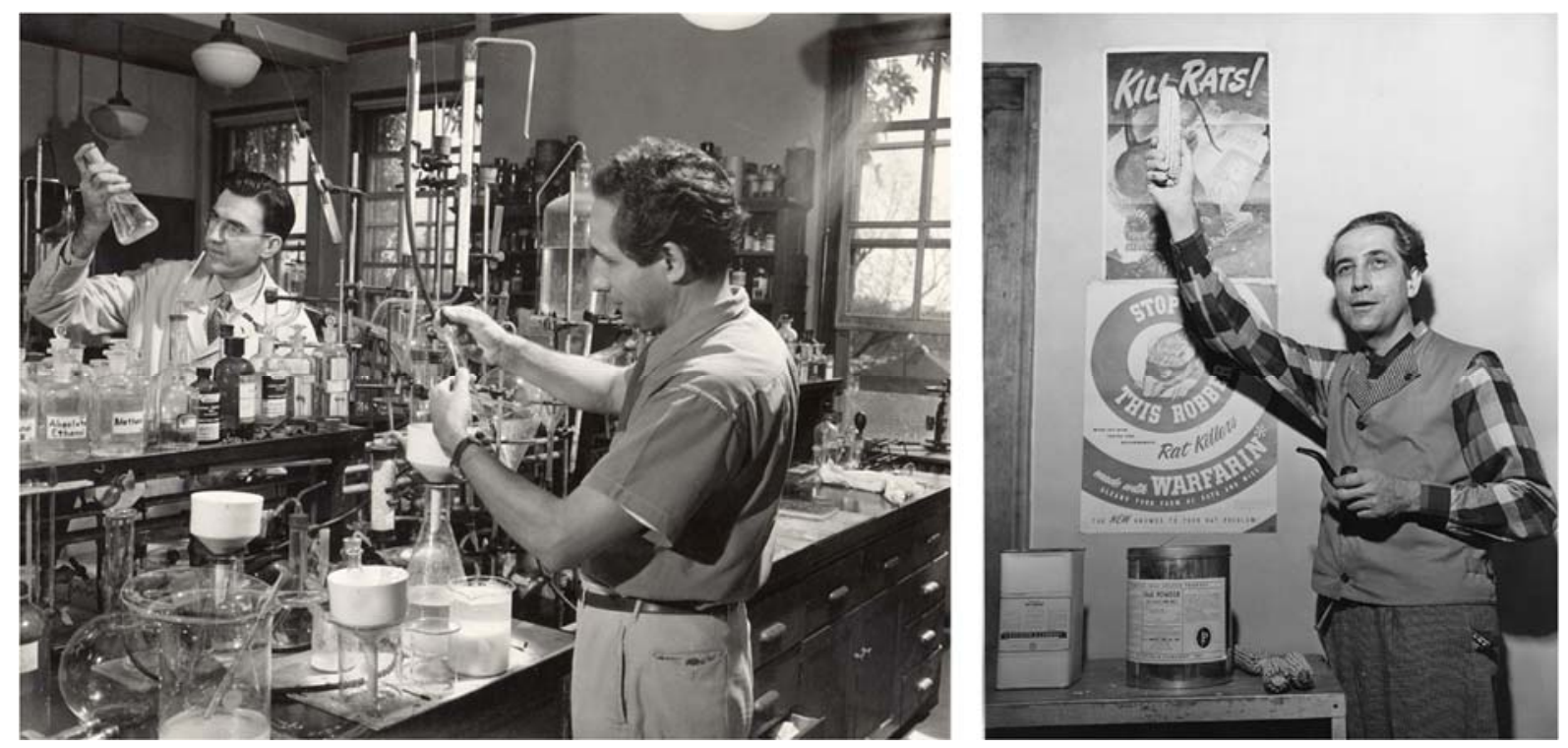

Figure S3. Karl Paul Link working in his laboratory and standing in front of a poster advertising warfarin as rodenticide. Courtesy of the University of Wisconsin-Madison Archives (ID S05108 and S00093). 
After its success as "rat poison", warfarin was used as anticoagulant. This molecule presented several advantages over other available anticoagulants. Warfarin is a highly water soluble and highly orally bioavailable molecule and the main candidates at that time, heparin and dicoumarol, did not present these characteristics ${ }^{4}$. Heparin required parenteral administration and dicoumarol had a high latent time before reaching its therapeutic effect. Additionally, warfarin effect could be reversed by using vitamin K. In 1953 this molecule was used to treat the US President Eisenhower after a coronary thrombosis. Since then, this molecule has been widely used worldwide as oral anticoagulant ${ }^{4}$.

Vitamin $\mathrm{K}$ could reverse the effect of Warfarin as the mechanism of action of the drugs is based on limiting the available vitamin $\mathrm{K}$ that is involved in the production of several factors required for blood coagulation ${ }^{8}$.

This case is a good example for the students. It shows a different type of drug discovery, isolation rather than pure chemical synthesis. Besides it shows a good example of hard work and perseverance. Finally, it shows again how technical limitations should not stop scientific discoveries.

During the 6 years that Link and his team used to extract dicoumarol they carried out long extraction protocols and complex analytical procedures to determine the chemical structure of the molecule. The concentration and extraction process was developed in 16 steps (Figure S4) $)^{5-7}$. After a long isolation process, dicoumarol was isolated. To determine the structure of the molecule Link et al. used classical techniques as again, NMR or MS were not available. They started with elemental analysis, electrometric titration and they measured the melting point of the isolated substance. With the results obtained from these analyses, they find out that the empirical formula of the compound was $\mathrm{C}_{19} \mathrm{H}_{12} \mathrm{O}_{6}$, it had two hydroxyl groups and that the melting point was around $289^{\circ} \mathrm{C}^{5}$. Subsequently, in order to determine the structure of dicoumarol, they follow a similar procedure than the one followed by Sternbach: they fragmented the molecule and analyzed the fragments ${ }^{7}$. After doing this, Link and co-workers determined the structure of dicoumarol. Finally, the last step was to synthesize in the lab that molecule and ascertain if the synthetic dicoumarol had the same anticoagulant activity to the extracted one ${ }^{7}$. 


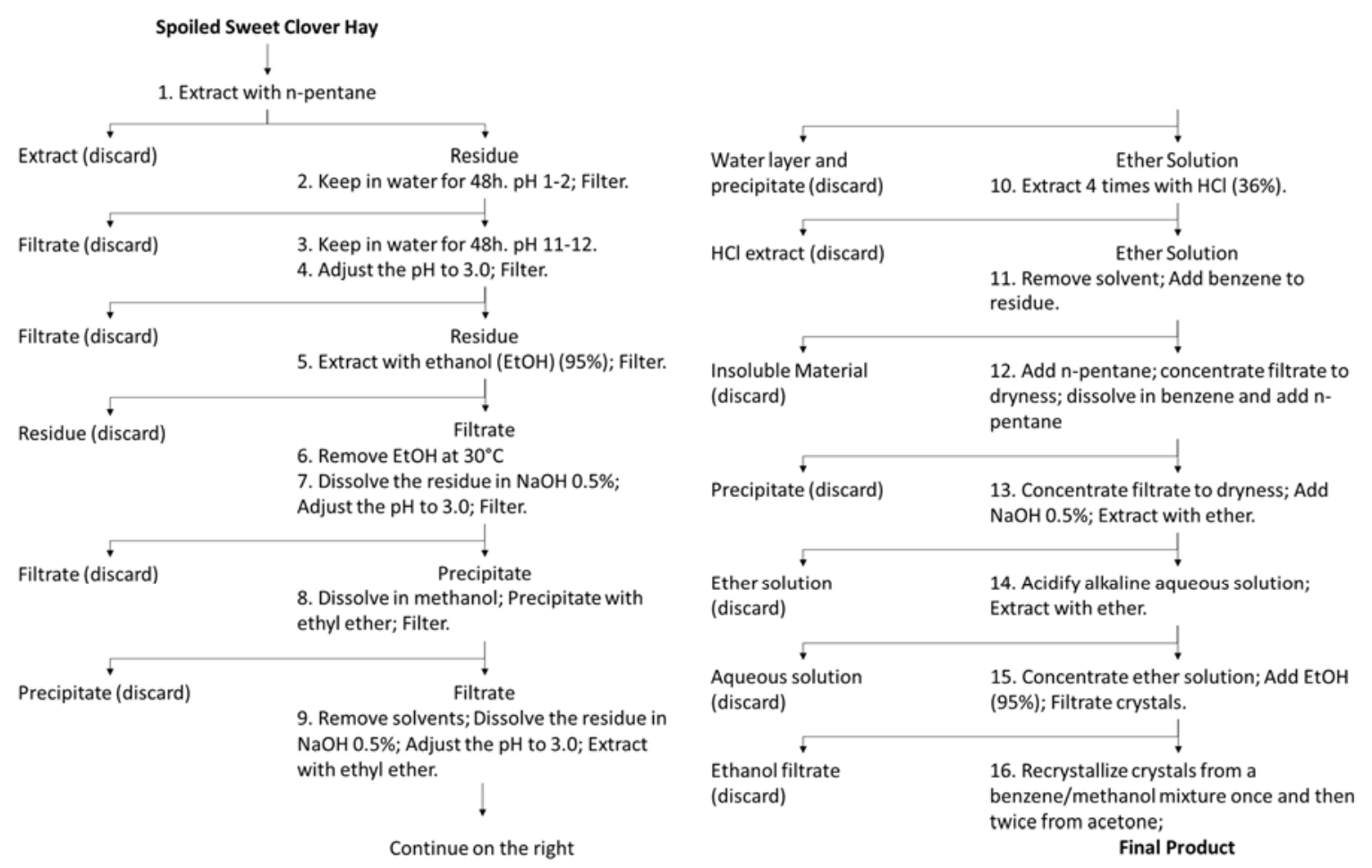

Figure S4. Extraction protocol followed by Link and co-workers to isolate the haemorrhagic agent obtained from the original 1940 s papers $^{5,6}$.

\subsection{History of Neuromuscular Blocking Drugs.}

Neuromuscular blocking agents are drugs commonly used during general anaesthesia. After administration, these compounds cause muscle relaxation. The discovery of these drugs changed the practice of anaesthesia ${ }^{9}, 10$. Before their discovery, when muscle relaxation was needed it was obtained using higher levels of anaesthetic. As a consequence of this, undesired side effects could appear such as: respiratory or cardiac depression ${ }^{10}$.

The discovery of this type of compounds started in the 16th century in Central and South America. Spanish conquistadors brought back home from their trips to the "New World" tales about the mysterious "flying death". Pietro Martired'Anghera, a chronicler in the Court of King Fernando and Queen Isabel, described in his 1516 book "De Orbe Novo" how Spanish soldiers died mysteriously after being hit by poisoned arrows thrown by the natives ${ }^{10}$. However, the cause of the death and the nature of the substance impregnated in the arrows were still unknown. Another historical reference to this poison can be found in a book written by a British explorer, Sir Walter Raleigh. This book was written after an expedition to Venezuela in 1594. In this book the name and the origin of the "poison" was described. The substance was called "ourari" and it was extracted from plants ${ }^{10}$. However, the original name was subsequently modified by Europeans to try to adapt the native word. Nowadays the substance is known as 
curare $^{10}$. Some curare pots used by the South American natives can be found in different museums around the world. Figure S5 shows a picture of one of them.
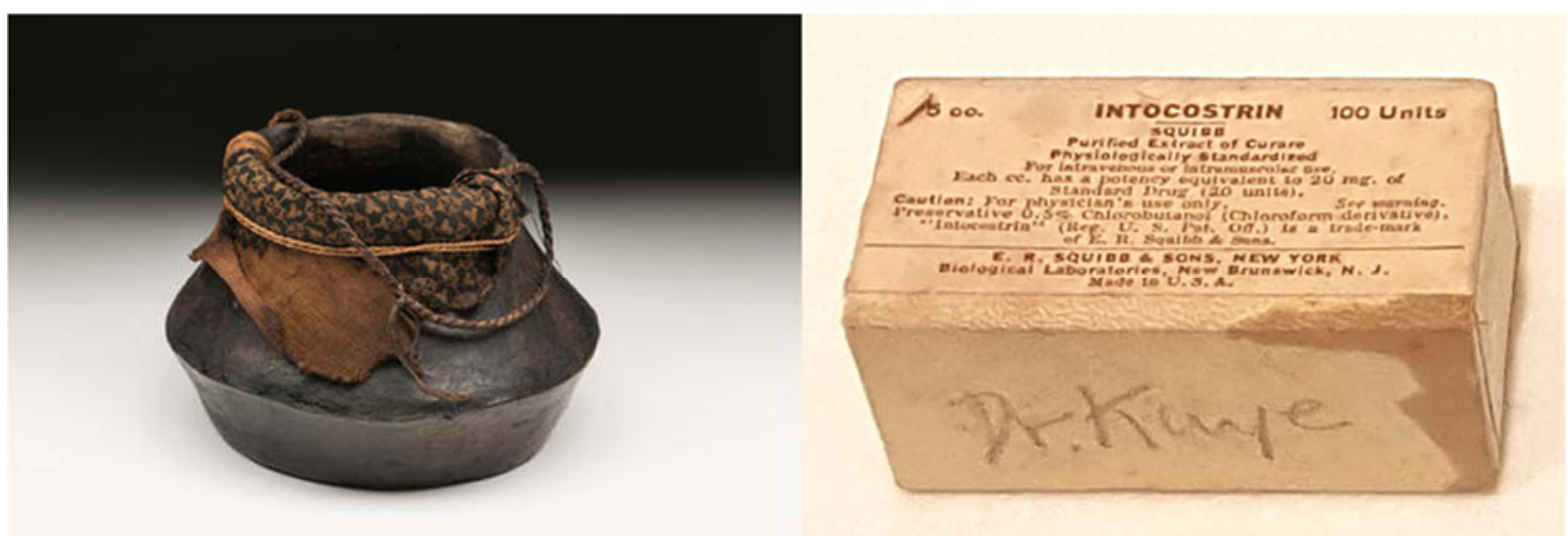

Figure S5. A curare pot from the early 20th century on display in the American Museum of Natural History's special exhibition The Power of Poison@ AMNH/D. Finnin. Intocostrin $®$ box image courtesy of the Geoffrey Kaye Museum of Anaesthetic History.

The first systematic studies about curare took place during the 18 th century ${ }^{10}$. Some researchers brought back some crude curare samples to Europe and started to study its effects in animals. The substance was proven to be able to kill small and big animals. However, the animals could be kept alive after a curare injection by artificial ventilation of their lungs using bellows. In 1846 Claude Bernard published a study showing that, after an experiment with curare on frogs, he discovered that curare acted at the nerve-muscle junction preventing muscle contraction ${ }^{10}$.

All these experiments were performed with curare extracts. The study of the molecules behind the muscle relaxation effect started with the work of Harold King in 1935', 10 . He isolated the molecule d-tubocurarine from a museum sample of curare. He established that the molecule contains two quaternary ammonium groups. This was consistent with the 1860 s discovery showing that some alkaloids such as atropine, brucine or morphine acquired curare-like activity after changing its amine groups from tertiary to quaternary form ${ }^{10}$.

In 1942, the molecule d-tubocurarine was first extracted and isolated from plants by researchers at E R Squibb and Sons, a USA pharmaceutical company that became part of the modern Bristol-Myers Squibb ${ }^{10}$. The plant samples were collected and donated to this company by an American suffering from multiple sclerosis, Richard Gill. He thought that curare could be useful to develop a cure for his condition. Scientist at Squibb and Sons developed a commercial preparation of curare, Intocostrin ${ }^{\circledR}$. Figure S5 includes a picture of this product. 
The first clinical uses of this molecule took place during the $1940 \mathrm{~s}^{10}$. It was successfully used in anaesthesia for several surgical procedures. During these procedures, it was apparent that due to the muscle relaxant activity of curare, patients had to be ventilated manually to prevent them stopping breathing. The introduction of curare as muscle relaxant was a revolution for anaesthesia. The first studies of muscular relaxant agents pointed that they presented two quaternary ammonium groups separated by an optimum distance. This main feature was considered by medicinal chemists in different research group for the development of new and improved muscular relaxant drugs.

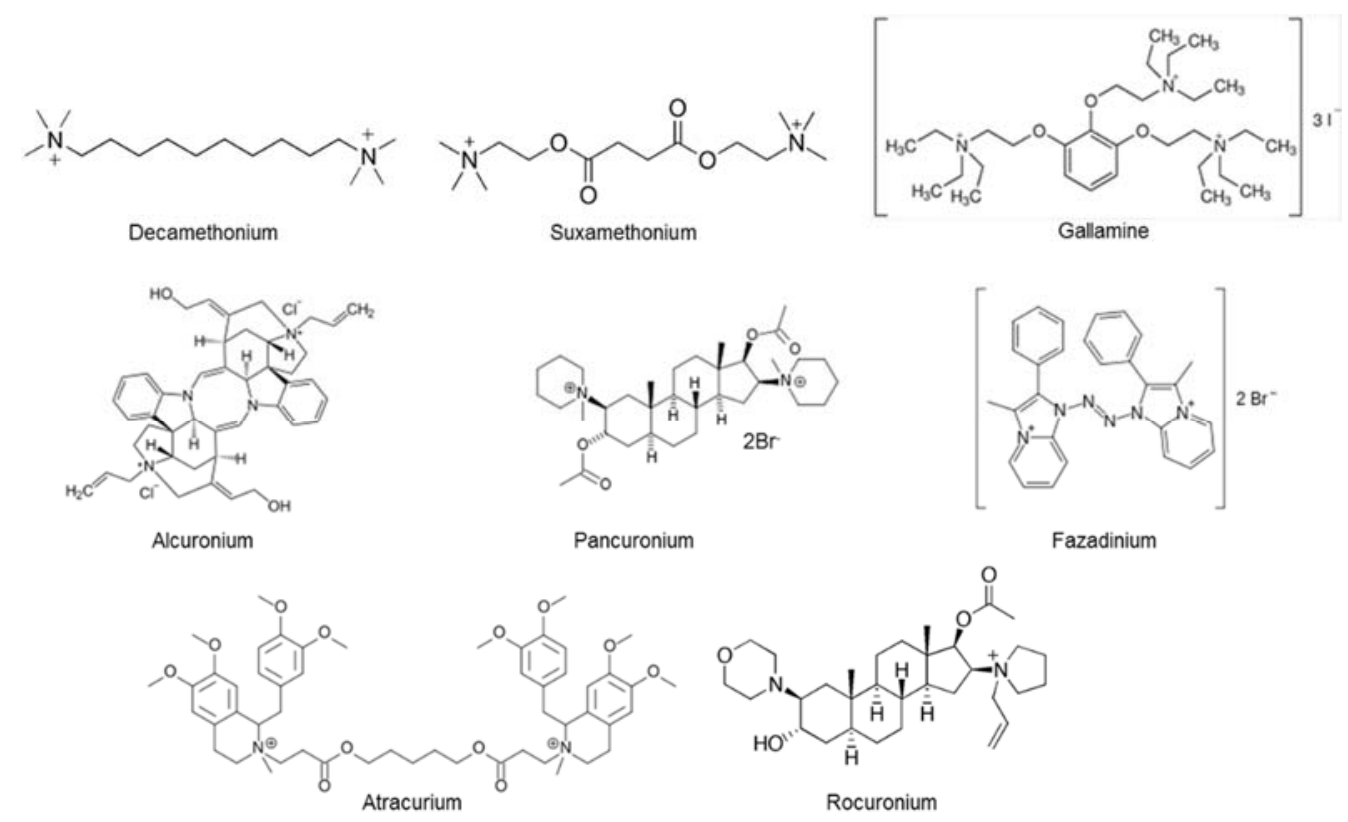

Figure S6. Quaternary ammonium salts used in clinical practice.

Between 1945 and 1990 a number of synthetic bisquaternary ammonium salts were successfully introduced into clinical practice (Figure S6) ${ }^{10}$. Due to the two charged amine groups these compounds are able to block transmission through the neuromuscular junction competing with acetylcholine for nicotinic receptor binding sites, thus decreasing skeletal muscle tone ${ }^{11}$.

This case study allowed me to introduce some exercises about separation and quantification of mixtures as curare was a compound extracted from a natural source. While describing all the extraction and identification of the active molecule behind the effect of curare, I proposed a new exercise to the students. I ask them to think of a method to simultaneously determine the amount of 4 anticancer compounds within a medicinal plant (Figure S7). After allowing the students to think about this issue, I asked some of them to describe a method to accomplish 
this task. The idea behind this question was obtained from a research paper where HPLC was used for this purpose ${ }^{29}$. This paper describes a method that allows to determine simultaneously several alkaloids from Vincarosea plant extracts. Consequently, I showed the paper to the students and summarized it during the lecture. This exercise reinforced the idea of how HPLC as a separation technique for complex mixtures is important. Finally, another research work was showed to the students to highlight that HPLC can be used to quantify the levels of one of the neuromuscular blocking drugs inspired by d-tubocurarine (atracurium). This work was focused on the development of a method to quantify this drug in plasma for infants and children ${ }^{30}$. This paper was clinically relevant for pharmacy students and showed how to develop a highly sensible method to quantify the drug as the plasma volumes are lower than the samples extracted for adults.
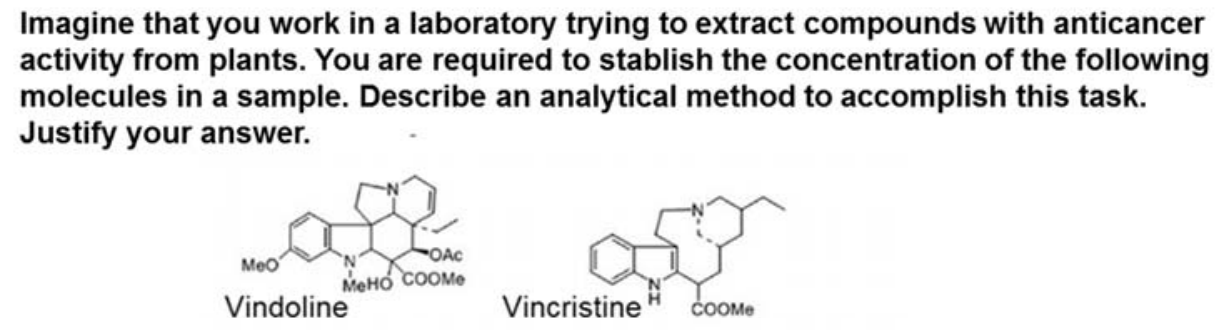

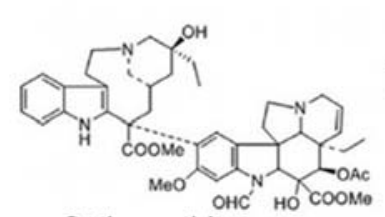

Catharanthine

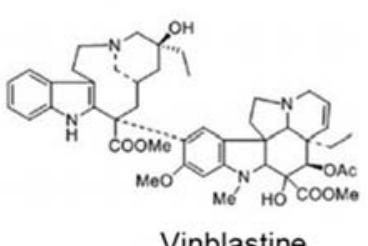

Vinblastine

Figure S7. Question proposed to the students during the neuromuscular blocking drugs case study. 


\section{Student's opinion about the drug discovery case studies}

\subsection{Academic year $2017-2018$}

The questionnaire administered to the students in 2017 has a section to include comments. Table S1 shows a selection of the main positive, negative and mixed comments obtained.

Table S1. Representative positive, mixed and negative comments obtained from a questionnaire filled by the student after the historical case studies of drug discovery during the 2017-2018 academic year.

\begin{tabular}{|c|c|}
\hline $\begin{array}{l}\text { Possitive } \\
\text { Comments }\end{array}$ & $\begin{array}{l}\text { The history didn't really impact on my understanding, but it definetely stimulated } \\
\text { my interest in the subject }\end{array}$ \\
\hline & $\begin{array}{l}\text { I appreciate the history of the techniques and drug discovery as it is a change up } \\
\text { from the normal routine lectures. It keeps things interesting and enriching } \\
\text { I agree with the inclusion of history as it is important to see how "mistakes" were } \\
\text { solved. } \\
\text { I found this useful in furthering my understanding of the topic. It also made the } \\
\text { material more interesting and easier to follow. } \\
\text { It makes it more interesting }\end{array}$ \\
\hline $\begin{array}{l}\text { Mixed } \\
\text { Comments }\end{array}$ & $\begin{array}{l}\text { Historical perspective was emphasized a little too much. The examples and case } \\
\text { studies were really helpful. }\end{array}$ \\
\hline $\begin{array}{l}\text { Negative } \\
\text { Comments }\end{array}$ & $\begin{array}{l}\text { I find the content of the lectures not interesting. } \\
\text { The subject doesn't interest me. }\end{array}$ \\
\hline
\end{tabular}

\subsection{Academic year $2016-2017$}

The three described examples were delivered to $3^{\text {rd }}$ years students of Pharmacy and Pharmaceutical Sciences degrees in a chemistry module. After finishing the lecture series, a questionnaire was given to the students to evaluate their opinions about the content of the lectures. The study was approved by the Queen's University Belfast School of Pharmacy Ethics Committee (Ref: 022PMY2016). The three main questions were included in the questionnaire can be seen in Table S2. The obtained results (Table S2) showed that the majority of the students were satisfied with the lectures and thought that knowing the history behind their scientific discipline was important. However, it needs to be taken into account that a percentage between the 30 and $40 \%$ of the students were not fully happy with the approach taken to delivery this material. 
Table S2. Results obtained in a questionnaire filled by the student after the historical case studies of drug discovery.

\begin{tabular}{lll}
\hline Question & $\%$ Yes & $\%$ No \\
\hline $\begin{array}{l}\text { Do you think that an understanding of the history } \\
\text { behind your discipline is important? }\end{array}$ & 33.3 \\
Do you believe that including an outline of the 60.8 & 39.2 \\
history of the scientific development of your subject & \\
has improved your overall understanding of the & \\
subject? & \\
Did you find the inclusion of this material beneficial & 65.3 & 34.7 \\
to your studies as Pharmacist/Pharmaceutical & \\
Scientist? &
\end{tabular}

The questionnaire had a section to include the student opinion about the lectures. Table S3 summarizes the more relevant positive, negative and mixed comments. By reading some of the additional comments obtained in the questionnaire, the majority of the students that were not fully happy with the lectures were not seeing the utility of these lectures for their future as community pharmacist or clinical pharmacist (Table S3). On the other hand, the positive comments and part of the mixed comments were consistent with the initial objectives established for the lectures. The historical cases stimulated the interest of the students and additionally they thought that the lectures make them appreciate the current analytical techniques.

Table S3. Representative positive, mixed and negative comments obtained from a questionnaire filled by the student after the historical case studies of drug discovery during the 2016-2017 academic year.

Possitive The inclusion of historical developments in the module stimulates my interest in Comments knowing more about pharmaceutical analysis, and it makes me appreciate more the current analytical methods that we have

I can see the development of modern technology and the importance of development in designing new therapeutics

It provides background information on how things come about. It's not essential but provides a good thorough understanding

Understanding the history will help me to understand the advancements of pharmaceutical analytical methods

Provides better understanding and foundation for the material taught 
Learning the topic is more interesting when you know the history behind the drugs

Makes learning more interesting and puts everything into perspective

History provides context and stimulates an interest in the topic. Makes material easier to understand and remember

\begin{tabular}{ll}
\hline Mixed & It helped in understanding of developments in modern medicine but didn't aid my \\
Comments & study as a pharmacist \\
It helps us to learn the lecture materials but will not benefit us in our career as \\
pharmacist \\
In practice, the history of the subject will never come into use when treating a \\
patient. However, it does help understand things \\
Interesting but not relevant to a careeer in Pharmacy but a to a chemistry degree \\
Maybe not totally relevant as topic but extermely benefcial and enjoyable to hear. \\
Adds better understanding to the field \\
I am not interested in industrial side of pharmacy but in its clinical-patient care in \\
Negative \\
community \\
I do not understand how the inclusion of historical material will benefit our future \\
as pharmacists \\
This was not relevant to our careers as community pharmacist \\
I think learing about science nowadays is more important \\
It did not improve understanding \\
I don't find the material very relevant to what I want to do in the future as \\
pharmacist \\
I do not feel the material relevant to a practicing pharmacist in either community \\
or hospital \\
I am not aiming to be a Pharmaceutical Scientist
\end{tabular}

\section{Bibliography}

1. Tone, A. The Age of Anxiety: A History of America's Turbulent Affair with Tranquilizers; Basic Books: New York, 2008.

2. Sternbach, L. H. The benzodiazepine story. J. Med. Chem. 1979, 22, 1-7.

3. Mehdi, T. Benzodiazepines revisited. Br. J. Med. Pract. 2012, 5, 501.

4. Wardrop, D.; Keeling, D. The story of the discovery of heparin and warfarin. Br. J. Haematol. 2008, 141, 757-763. 
5. Campbell, H. A.; Roberts, W. L.; Smith, W. K.; Link, K. P. Studies on the hemorrhagic sweet clover disease I. The preparation of hemorrhagic concentrates. J. Biol. Chem. 1940, 136, 47-55.

6. Campbell, H. A.; Link, K. P. Studies on the Hemorrhagic Sweet Clover Disease IV. The Isolation and Crystallization of the Hemorrhagic Agent. J. Biol. Chem. 1941, 138, 21-33.

7. Stahmann, M. A.; Huebner, C. F.; Link, K. P. Studies on the hemorrhagic sweet clover disease V. Identification and synthesis of the hemorrhagic agent. J. Biol. Chem. 1941, 138, 513-527.

8. Freedman, M. D. Oral Anticoagulants: Pharmacodynamics, Clinical Indications and Adverse Effects. J. Clin. Pharmacol. 1992, 32, 196-209.

9. Caldwell, J. E. A History of Neuromuscular Block and Its Antagonism. In The Wondrous Story of Anesthesia; Eger, I. I., Saidman, L. J., Westhorpe, R. N., Eds.; Springer: New York, 2014; pp 671-691.

10. Raghavendra, T. Neuromuscular blocking drugs: discovery and development. J. R. Soc. Med. 2002, 95, 363-7.

11. Khirwadkar, R.; Hunter, J. M. Neuromuscular physiology and pharmacology: an update. Continuing Education in Anaesthesia Critical Care \& Pain 2012, 12, 237. 